\title{
Supplementary materials of the manuscript
}

Montmorillonite Clay Nanocomposites of Sulphonic Acid Doped Thermoreversible Polyaniline Gel: Physical and Mechanical Properties 


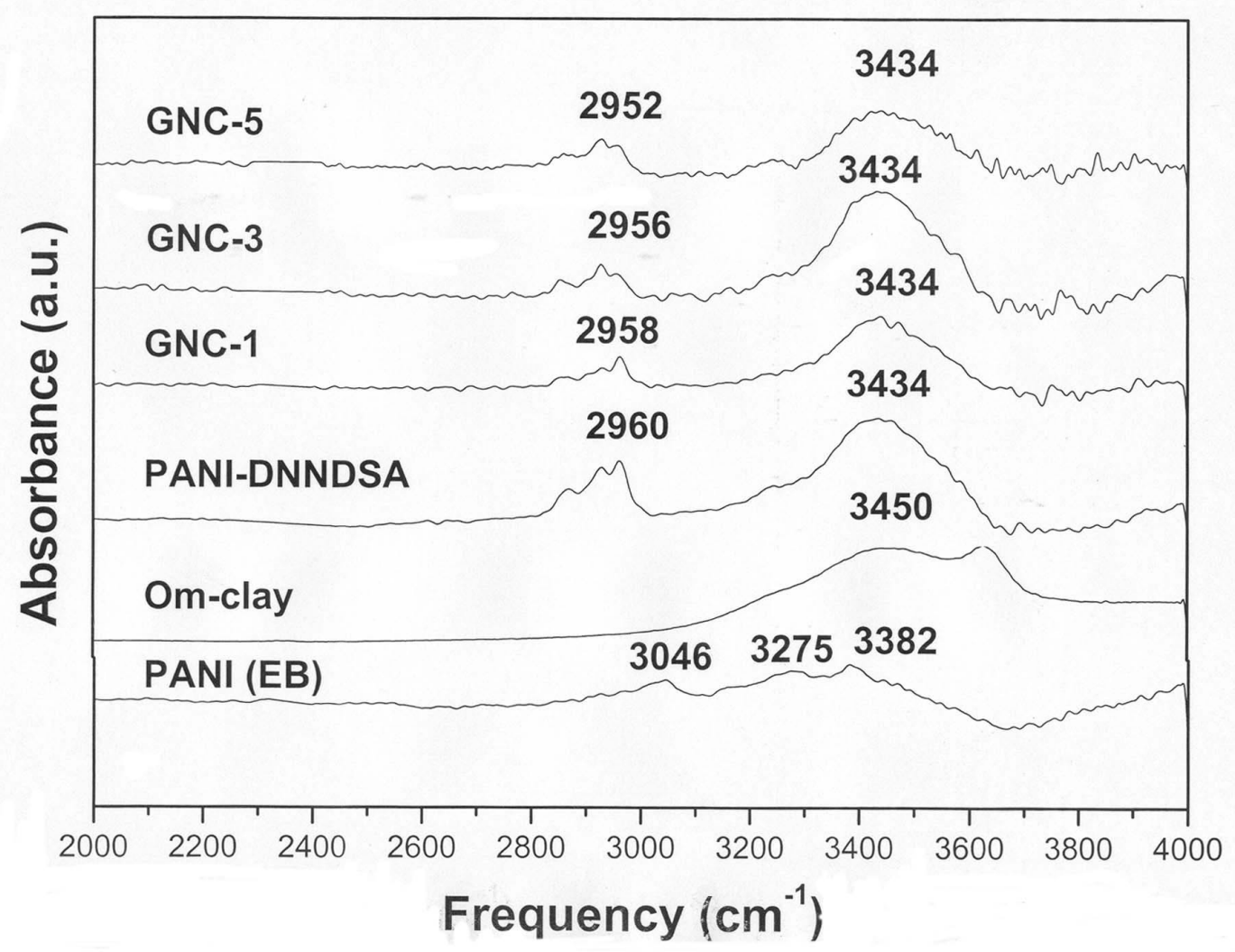

Supplimentary Fig-1: FTIR spectra of dried PANI-DNNDSA gel and GNCs, indicating absence of formic acid and isobutanol. 


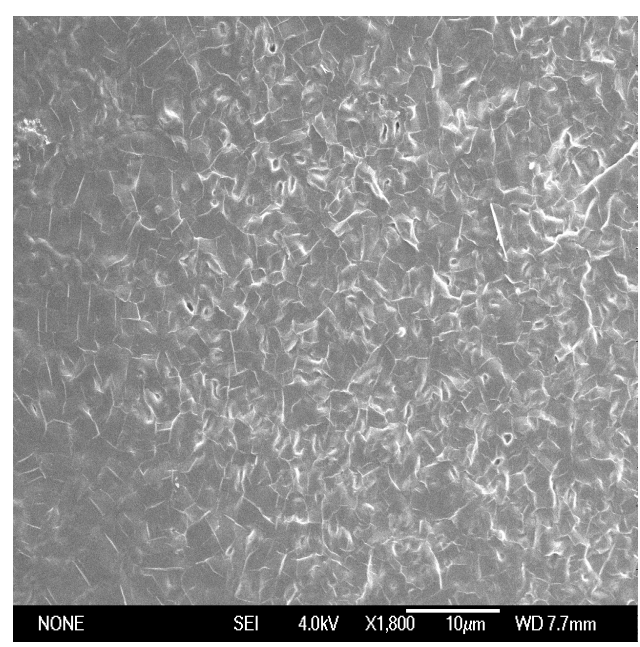

PANI-DNNDSA

(a)

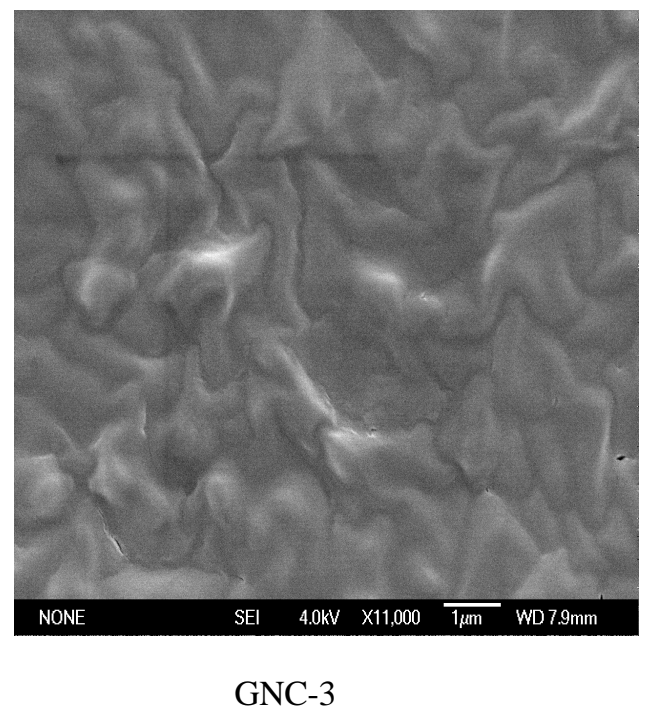

(b)

Supplementary Fig-2; Scanning electron micrographs of dried samples (a) PANI-DNNDSA and (b) GNC-3. 


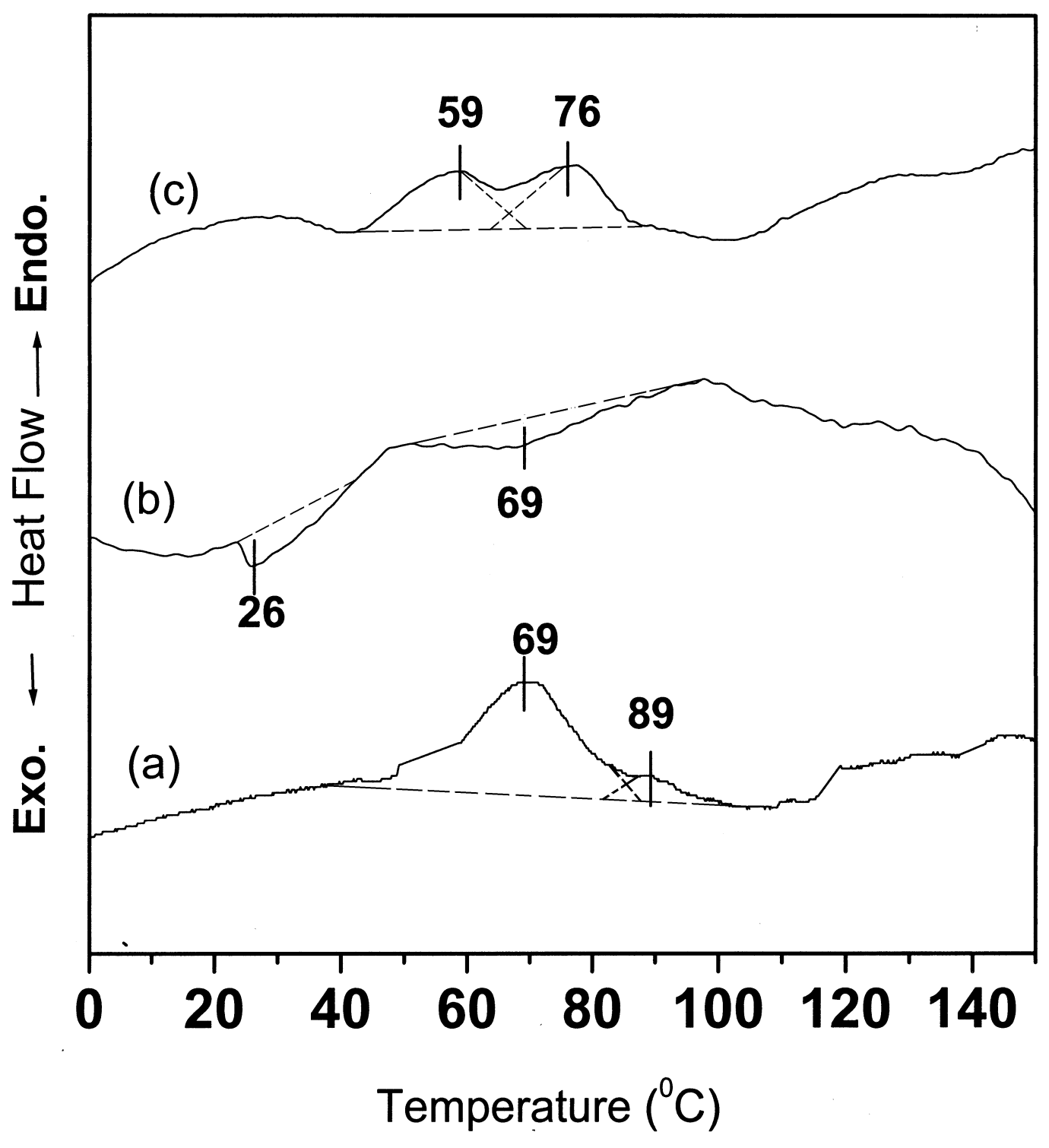

Supplementary Fig-3 (a). DSC thermograms of GNC-3 (a) first heating of the as prepared gel (heating rate $10^{\circ} \mathrm{C} / \mathrm{min}$ ) from $-20^{\circ} \mathrm{C}$, (b) cooling from $160^{\circ} \mathrm{C}$ at the cooling rate $5^{\circ} \mathrm{C} / \mathrm{min}$ up to $-20^{\circ} \mathrm{C}$ and (c) second heating of the gel prepared at $20^{\circ} \mathrm{C}$ for 15 minutes at the scan rate $10^{\circ} \mathrm{C} / \mathrm{min}$. 


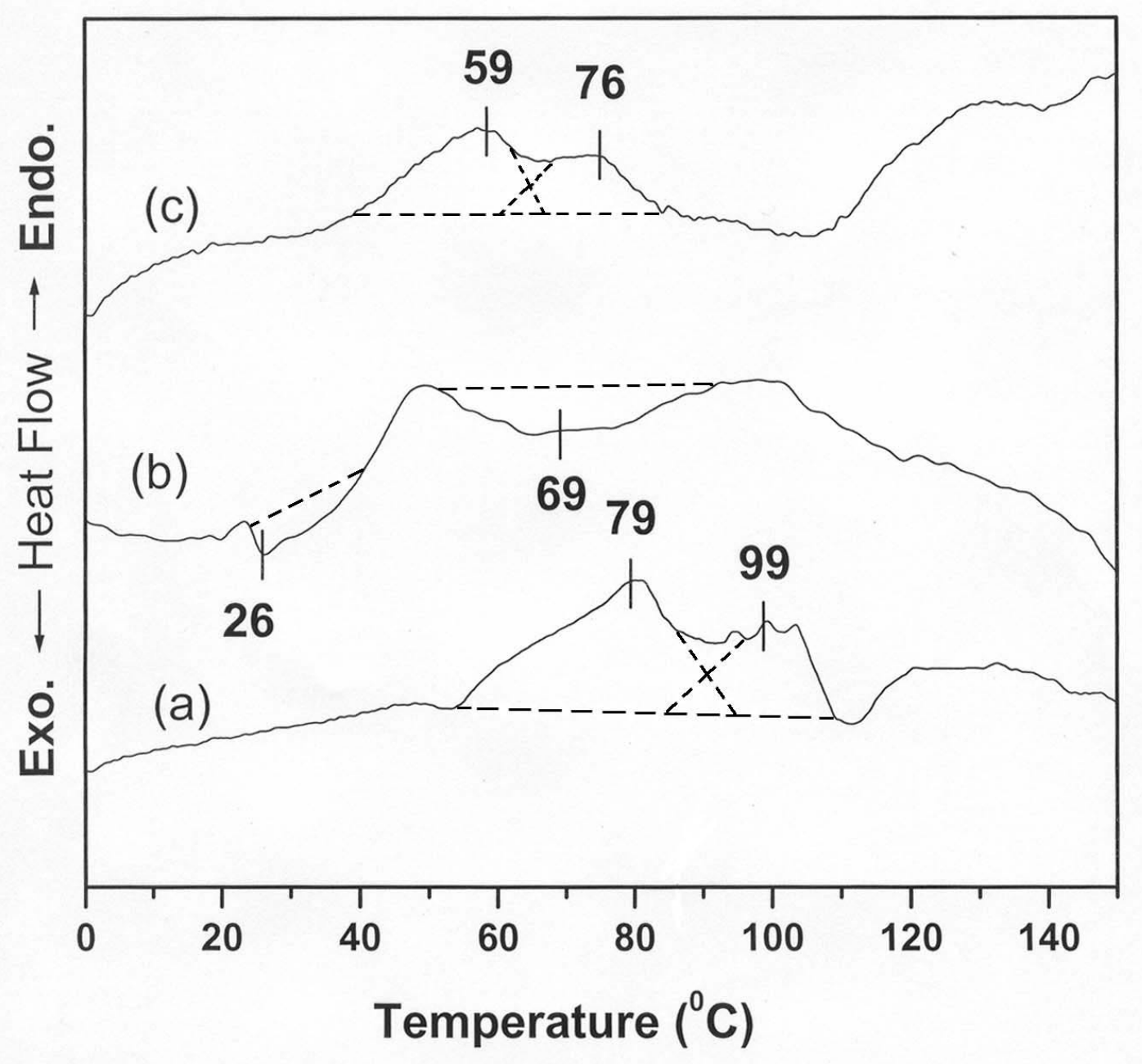

Supplementary Fig-3 (b). DSC thermograms of GNC-5 (a) first heating from $-20^{\circ} \mathrm{C}$ of the as prepared gel (heating rate $10^{\circ} \mathrm{C} / \mathrm{min}$ ), (b) cooling from $160^{\circ} \mathrm{C}$ at the cooling rate $5^{\circ} \mathrm{C} / \mathrm{min}$ up to $-20^{0} \mathrm{C}$ and (c) second heating of the gel prepared at $-20^{\circ} \mathrm{C}$ for 15 minutes at the scan rate $10^{\circ} \mathrm{C} / \mathrm{min}$. 